\title{
Evocación antropológica de la novelística de la Condesa de Pardo Bazán
}

\author{
JOSÉ ANTONIO FERNÁNDEZ DE ROTA Y MONTER \\ Dpto. de Humanidades \\ Universidad de la Coruña
}

\section{RESUMEN}

Emilia Pardo Bazán junto con Ramón M. del Valle-Inclán son quizá los dos literatos gallegos que aportan en sus obras una mayor riqueza y profundidad etnográfica. Doña Emilia domina y expresa con excepcional acierto las íntimas complejidades de la vida social desde el interior de la vida cotidiana de las familias. Desde allí contempla la micropolítica aldeana en sus entresijos de jerarquías y estrategias sociales. La economía cobra calibre cultural con todas sus virtualidades de comunicación a través de elementos simbólicos. Este artículo analiza la fuerza argumental antropológica de sus novelas más destacadas y la capacidad de sintonía y rigor de sus descripciones costumbristas. Se hace un contraste de su obra con los estudios recientes de la Antropología Social de la que es precursora y a la que dota, con su obra, de profundidad histórica.

Palabras claves: Etnoliteratura, Narrativa, Emilia Pardo Bazán.

\section{SUMMARY}

Emilia Pardo Bazán and Ramón M. del Valle-Inclán are perhaps the two Galician novelists who provide us with the richest and most profound ethnographical insight in their works. Doña Emilia understood and successfully expresses the intimate complexities of social life from the inside of every-day family life, as she contemplates the micropolitics of rural communities, with their hierarchies and social strategies. In her novels, the economy gains a cultural tone with its virtualities of communication through symbolic elements. Fernández de Rota addresses the anthropological coherence and strength of her best known work and her ability to tune in to the people while describing folklore rigorously. A comparison is then made with the current research of social nnthropology in the area, of which she is a forerunner and which her work endows with historical depth.

Key words: Ethnoliterature, Narrative, Emilia Pardo Bazán.

Fue sin duda mérito de Manuel de la Fuente Lombo (1994; 1997) el captar como pocos en España la profunda relación existente entre etnografía y ciertos tipos de literatura. El tema ha sido evocado, discutido y

RDTP, LX, 1 (2005): 123-139 
elaborado de distintas formas por parte de la antropología anglófona. Entre otras formas, cabe sin duda la inmediata relación con la obra literaria por parte del etnógrafo como forma que permite una nueva interpretación de los textos literarios y un aprovechamiento como riqueza etnográfica de su narración. Pero no sólo esto, como trataba de mostrar Manuel a través de su insistente organización de seminarios de etnoliteratura, la comparación entre literatura y antropología nos permite importantes reflexiones sobre distintas maneras de hacer etnografía. Es decir sobre distintos modos de descubrir y explicar la vida social y cultural. La vida humana que nos rodea, la captamos con una sensación de inmediatez, los "hechos" nos aparecen como realidades que hacemos complejas dentro de determinados marcos culturales. Cuando tratamos de comprender y explicar la vida de los demás, nos encontramos con que ellos también han categorizado y ordenado su mundo, y para actuar y hablar de él, se apoyan en esas categorías y ese orden. Este diálogo entre su mundo y el nuestro es esencial, tanto a la obra literaria, como a la monografía antropológica. Por supuesto, a la hora de escribir un texto, tenemos también los condicionantes propios de una obra escrita y debemos atender a los posibles lectores a los que dirigimos nuestro texto.

Ordinariamente, consideramos que la obra literaria se diferencia de la antropológica por la mayor libertad de la primera en cuanto a inventiva y ficción. Esto en general es verdad, pero una comprensión simplista de esta aseveración puede desorientarnos. La obra literaria llega a interesarnos profundamente, en la medida en que sea capaz de transmitir, de uno u otro modo, una mayor comprensión acerca de la realidad de la vida humana. Hasta la más disparatada invención, de forma directa o a través de la ironía, la hipérbole, la metáfora... tiene que ser capaz de decir algo acerca de la real vida humana. Hay un realismo de fondo, que debe de ser evocado a través de medios alternativos de transmitir interpretación. A veces las formas más imaginativas, aparentemente más libres e independientes de una inmediata conexión con nuestra tangible realidad, exigen un extraordinario esfuerzo suplementario de precisión formal y de aguda capacidad de evocación de reales problemas del hombre y de la sociedad, y suministran muchas veces nuevas posibilidades de comprensión del simbolismo cultural.

Evidentemente, la cercanía entre ciertos géneros y corrientes de literatura y de antropología es más manifiesta que en otros. Por parte de la antropología, muchos autores consideran de gran importancia el utilizar un estilo literario en sus escritos e incluso, en algunos, su forma de presentación de materiales descriptivos se hace de acuerdo con técnicas tomadas de determinados géneros literarios. En los últimos años, ha cobrado un 
especial interés la atención a la manera de escribir de los antropólogos y la utilización de métodos propios de la crítica y teoría literarias para analizar sus trabajos y plantear las formas de expresión literaria que se consideran más adecuadas. Dentro de este marco de complejas inquietudes, voy a plantear aquí, como análisis, un caso concreto. Me centraré en el díptico famoso de $\mathrm{D}^{\mathrm{a}}$ Emilia Pardo Bazán: Los Pazos de Ulloa y La madre naturaleza. Su estilo, cercano al naturalismo, es sin duda más parecido a la descripción etnográfica. Dialogaré con ella, desde mi personal experiencia de trabajo de campo en la ruralía gallega y su estudio, concebidos bajo la perspectiva de una antropología interpretativa.

D. ${ }^{\text {a }}$ Emilia nos describe el mundo rural gallego de fines del XIX, un siglo antes de iniciar mi trabajo de campo en un área del interior de Galicia no lejos de la comarca de la Ulloa. En ambas novelas, nos introduce en este ambiente, a partir de las vivencias de protagonistas provenientes de la vida urbana. En Los Pazos de Ulloa, será el capellán -D. Julián- introvertido y místico, que llega de Santiago para prestar sus servicios religiosos en el viejo caserón habitado por un aristócrata aldeano, solterón "adocenado", amancebado, con su criada Sabel y dedicado a la caza. D. Julián consigue que el Señor de Ulloa se case con una prima suya - Nuchatambién santiaguesa, que desembarca en el asfixiante ambiente de contortas y cerradas intrigas humanas del pazo. En La madre naturaleza, veinte años después de haber muerto Nucha, llega, persiguiendo su recuerdo, su hermano menor D. Gabriel, militar culto y cosmopolita. Estos protagonistas venidos de la ciudad cuentan para su introducción en el desconocido mundo campesino con destacados intermediarios: otros curas, el propio Señor de Ulloa -D. Pedro Moscoso-, el médico, algunos "caciques", la hija legítima de Nucha y D. Pedro -Manuela-, el hijo bastardo de Sabel y D. Pedro - Perucho-. Por último se nos presentan diferentes tipos campesinos, observados desde fuera y con mayor superficialidad.

Este conjunto de personajes y sus dinámicas tensiones son comprendidos dentro de una atmósfera cultural minuciosamente descrita, y situados en sus estructuras socioeconómicas a través de una secuencia, en que la historia política del país es contemplada también en sus repercusiones en el microcosmos de la vida concreta de los alrededores del pazo. La narración, apoyada en soporte biográfico, nos permite remansarnos continuamente en el vivir cotidiano de las gentes en cuya vida nos introduce. Veamos qué aspectos de la realidad rural llaman la atención de la autora; en qué se fija y selecciona; qué ha observado y preguntado. Esa selección de intereses, de datos, y la búsqueda de relaciones interpretativas, que podemos atisbar a través de sus novelas, nos van a dar la dimensión de la Condesa de Pardo Bazán como etnógrafa. 
Acompañemos a la autora en su descripción del Pazo de Ulloa, a través de la mirada y las experiencias de su protagonista, D. Julián, el capellán novel recién llegado de Santiago, guiado por el Señor de Ulloa y su mayordomo. Después de haber pasado por la bodega:

llegaron presto a la espaciosa cocina alumbrada por la claridad del fuego que ardía en el hogar, consumiendo lo que se llama arcaicamente un mediano monte de leña [...] Adornaban la elevada campana de la chimenea ristras de chorizos y morcillas, con algún jamón de añadidura, y a un lado y otro sendos bancos brindaban asiento cómodo para calentarse, oyendo hervir el negro pote, que, pendiente de los llares, ofrecía a los ósculos de la llama su insensible vientre de hierro.

La descripción de la cocina se irá completando en distintos aspectos. La cocina está iluminada tan sólo por la claridad que da el fuego del hogar y de esta forma, la oscuridad es tan notable que difícilmente se descubre a las personas o se las ve entrar y salir, sobre todo cuando están alejadas del fuego. Es esta sensación de oscuridad de las viejas casas rurales uno de los elementos con los que mis informantes mayores evocaban etapas de su niñez. En muchas casas, dada la falta de ventanas, la oscuridad era grande incluso en pleno día. Es, sin duda, una oscuridad menos llamativa para una autora del siglo XIX que ha vivido antes de la invención de la electricidad. Con todo, el sistema de alumbrado de una vivienda urbana acomodada debía de contrastar notablemente con una cocina como la que aquí se describe. Jamones y embutidos están colgados en la campana de la chimenea, aprovechando el humo que contribuye a su conservación.

La casa —dirá el dueño- es la "más grande del país". Es una casa aristocrática, aunque impregnada de ambiente aldeano, y las características definitorias de su categoría son presentadas con nitidez: "En el esconce de la cocina, una mesa de roble, renegrida por el uso, mostraba extendido un mantel grosero, manchado de vino y grasan. La mesa del Señor de Ulloa, sucia y desaliñada, contrastará, en cambio, con los "cubiertos de antigua y maciza platan. Es este el lugar donde comen habitualmente el señor, los criados principales y otros acompañantes. Por contra, en las tertulias invernales, donde mujeres de la aldea van a visitar a las criadas del pazo y a las que se les convida también a caldo, nos dirá que, después de llenar sus cuencos, desaparecen del círculo central arefugiándose en la esquina o en un banco, donde se oía mascar ansiosamente, soplar el hirviente bodrio y lengüetear contra la cuchara. No sólo en la cocina del pazo, en sus propias casas, los labradores no solían comer a la mesa, sino con su cunca en la mano; las mujeres, con frecuencia, ni siquiera se sentaban, sino que se apoyaban en una esquina o recostaban contra 
algún saliente, tal y como aquí se describe. En una casa modesta, tan sólo se comía a la mesa -acodados na mesa - en los días de la fiesta, o comía así el jefe de la casa - Petrucio- con alguna visita importante. De esta manera, la acertada descripción que ella ha captado con singular precisión, en las casas solariegas, que conocía a la perfección, confirma las observaciones del antropólogo y cobra una mayor amplitud explicativa contextualizada en otros ambientes. Se trata de una manera de hacer, formalizada en la vida cotidiana, que jerarquiza rangos de personas o rangos de días dentro del calendario.

Desde el primer momento, tenemos el contraste de niveles sociales contrapuestos que se nos presentan ya en la misma cocina del pazo. Otras descripciones posteriores nos permitirán conocer toda una jerarquía de viviendas en las que aparecerán casas aristocráticas en plena decadencia, rectorales de parroquia, algunas viviendas rurales de profesionales de clase media y las más típicas viviendas de labradores. Su continuo empeño en manifestar en su descripción los elementos definitorios de estatus o las mezclas de características superpuestas en una misma vivienda, nos permiten una categorización y comprensión de elementos notablemente significativa. Veamos en detalle algunos de estos aspectos.

En primer lugar, la descripción del Pazo de Ulloa, referente de un pazo perteneciente al marido de la autora ${ }^{1}$, es realizada con extraordinaria minuciosidad. Es el propio capellán el que trata

de estudiar el mecanismo interior de los pazos; tomábase el trabajo de ir a los establos, a las cuadras, de enterarse de los cultivos, de visitar la granera, el horno, los hórreos, las eras, las bodegas, los alpendres, cada dependencia y cada rincón; de preguntar para qué servía esto y aquello y lo de más allá...

Con especial detalle se estudia el dormitorio que se adjudica al capellán y que nos permite entender la plasmación material de la obra constructiva en detalles bien significativos para quien vive allí. Así, el dormitorio no tenía "cielo raso", con lo cual se podía contemplar el duro entramado de vigas de madera que sostenía el tejado. A la hora de pedir D. Julián a la criada que barra el sucísimo dormitorio, le rogará que pase la escoba por las vigas de la techumbre para limpiar su polvo.

Pero $\mathrm{D}^{\mathbf{a}}$ Emilia aprovecha también la exploración del pazo para proyectarse hacia el exterior y comprender sus formas de dominio. Así, D. Julián se enfrascará en el maremagnum de papelotes del archivo de la casona señorial:

${ }^{1}$ Se trata al parecer del Pazo de "Banga" en las tierras montañosas del municipio do Carballiño (Ourense). 
[Los] cuadernos mugrientos y apestando a tabaco, donde su antecesor el abad de Ulloa apuntaba los nombres de los pagadores y arrendatarios de la casa, y al margen, con un signo inteligible para él sólo, o con palabras más enigmáticas aún, el balance de sus pagos.

El mundo de las rentas estaba aún organizado a través del complejo sistema de foros y arrendamientos, difícil de imaginar, tanto para el capellán, como para cualquiera que no se haya asomado a este laberíntico mecanismo:

perdíase en un dédalo de foros y subforos, prorrateos, censos, pensiones, vinculaciones, cartas dotales, diezmos, tercios, pleitecillos menudos de atrasos y pleitazos gordos de partija.

Es toda una síntesis terminológica del increible sistema de relaciones de arrendamiento, dependencia y mecanismos de pagos que ha mantenido su enrevesada organización hasta entrado el siglo xx.

Tenemos por tanto, una serie de perspectivas de la organización socioeconómica y juegos de poder, realizada desde la misma entraña de las aristocráticas y aldeanas habitaciones del Pazo de Ulloa. Contemplemos, a continuación, detalles de algunas otras viviendas que sus protagonistas visitan a lo largo de estas obras. En la campiña gallega, por debajo del esplendor de los pazos de la aristocracia rural y en competencia con algunas de las casas fuertes de labradores ricos, nos encontramos con las rectorales, viviendas que en algunos casos constituyen también ejemplos de magníficas casonas. La antigua riqueza del clero es contemplada en un momento histórico en que se ha iniciado su decadencia. Acompañemos a la autora y sus protagonistas en su visita a la rectoral del arcipreste de Loiro:

Era preciso, para ir a Loiro, internarse bastante en la montaña y seguir una senda llena de despeñaderos y precipicios, que sólo se hacía practicable al acercarse a los dominios del arciprestazgo, vastos y ricos algún día, hoy casi anulados por la desamortización. La rectoral daba señales de sus esplendor pasado; su aspecto era conventual; al entrar y apearse en el zaguán, los señores de Ulloa sintieron la impresión del frío subterráneo de una ancha cripta abovedada, donde la voz humana retumbaba de un modo extraño y solemne. Por la escalera, de anchos peldaños y monumental balaustre de piedra, bajaba dificultosamente [...] el arcipreste y su hermana.

Si la rectoral ha iniciado su decadencia, también visitamos con los recién casados señores de Ulloa, el pazo-palacio de la linajuda familia de los Limiosos, ya en plena decadencia:

Y con el decoro propio de un paso de minueto, la pareja entró por el pazo de Limioso adelante, subiendo la escalera interior que conducía al claustro, no sin 
peligro de rodar por ella: tales estaban de carcomidos los venerables escalones. El tejado del claustro era un puro calado; veíanse, a través de las tejas y la vigas, innumerables retales de terciopelo azul celeste [...] Fue peor cuando entraron en la antesala. Muchos años hacía que la polilla y la vetustez habían dado cuenta de la tablazón del piso; y no alcanzando, sin duda, los medios de los Limiosos a echar piso nuevo, se habían contentado con arrojar algunas tablas sueltas sobre los pontones y las vigas. $\mathrm{Y}$ por tan peligroso camino cruzó tranquilamente el señorito, sin dejar de ofrecer los dedos a Nucha.

El señorío del pazo y sus blasones nos aparecen entreverados con aspectos propios de la vida labradora:

En un ángulo de la sala medio desaparecía, bajo un acervo de trigo, un mueble soberbio, un bargueño incrustado de concha y marfil [...] Frente a la esquina del trigo se alzaba un estrado revestido de cuero de Córdoba, que aún conservaba su rica coloración y sus oros intensos; ante el estrado en semicírculo, magníficos sitiales tallados, con asiento de cuero también, y entre el trigo y el estrado, sentadas en tallos -asientos de tronco de roble bruto, como los que usan los labriegos más pobres—, dos viejas secas, pálidas, derechas, vestidas de hábito del Carmen hilaban.

Los protagonistas al salir del "goteroso pazo, callaron todo el camino, porque les oprimía la tristeza inexplicable de las cosas que se van".

Sin duda el conocimiento cercano y detallado de las clases acomodadas permite a la Condesa de Pardo Bazán recrearse con dominio, en magníficas y reveladoras descripciones. Es, sin duda, más difícil para ella el conseguir una tan completa penetración humana en el mundo de las casas más modestas, sin embargo es capaz de sorprender al lector con unas imágenes llenas de sugerencias. Son, sobre todo, dos casas las que describe en detalle en La madre naturaleza. Veamos los aspectos en los que centra su atención descriptiva. La primera casa que nos describe, es la de una Sabia: "Era una casucha baja y construida con piedras mal trabadas: adornábala principalmente un balcón o solana de madera". Nuestros protagonistas son invitados a entrar:

Tenía la casa piso de tierra; una escalera de madera conducía al sobrado o cuarto alto; y en el bajo se notaba una pintoresca mezcla de racionales e irracionales. El lar y la chimenea con asientos de madera bajo su campana; la artesa de guardar el pan; el horno de cocerlo; algunos taburetes con cuatro patas muy esparrancadas; la cuna de mimbres de una criatura, y el leito o camarote de tablas en que dormía el matrimonio que lo había engendrado, eran los muebles que pertenecían a la humanidad en aquel recinto. La animalidad invadía el resto. Al través de una división de tablones mal juntos pasaba el hálito caliente, el lento rumiar y los quejumbrosos mugidos del ganado; gallinas y pollos escarbaban el suelo y huían con señales de ridículo terror, renqueando, al acercárseles la gente [...] Un marrano sin cebar magro y peludo aún como un jabalí, sopeteaba con el hocico, gruñendo sordamente, en una tartera de barro donde nadaban berzas en aguachirle 
[...] en medio de esta especie de arca de Noé, reposaba inmóvil, sentada al pie de la artesa, con los naipes mugrientos al alcance de la mano, la vieja bruja de la Sabia.

La magnífica descripción nos presenta la casa labriega más típica en una amplia zona de las provincias de Coruña y Lugo. Este tipo de casa descrito por $\mathrm{D}^{\mathrm{a}}$ Emilia, a fines del siglo XIX, seguía siendo dominante en muchas aldeas del interior, en la época de la postguerra. A partir de los años cincuenta, se va dando un importante proceso de transformación de la vivienda rural. En mi trabajo de campo he podido conocer, en detalle y en plena vitalidad, un alto número de casas semejantes en las que tan sólo se habían introducido algunos aislados elementos modernizadores. He podido también visitar y estudiar numerosas casas ya abandonadas que presentaban, si cabe, con mayor pureza - aunque faltas de la presencia del vivir cotidiano- elementos característicos de esta descripción. Una de las impresiones más vívidas que producen estas casas es la presencia de la vida animal en estrecha relación con la familia humana. Como nos dice $D^{a}$ Emilia, "la animalidad invadía el resto". Sin duda, uno de los elementos más llamativos para el visitante exterior es la presencia y cercanía del ganado vacuno, cuyo "hálito caliente" y "quejumbrosos mugidos" pasaban en esta casa a través de "tablones mal juntos". Con mayor claridad se nos transmite esta impresión de cercanía en la descripción de la segunda casa:

$\mathrm{Al}$ entrar en la casa, lo primero que vio Gabriel fueron las cabezas de dos hermosos bueyes de labor, que asomaban casi a flor de suelo, saliendo de un establo excavado más hondo. A un lado y otro, haces de hierba.

Completemos la descripción de nuestra autora. La planta más común en este tipo de casas está dividida en dos mitades, una de ellas es la cocina y la otra la corte o establo de las vacas. El suelo de la corte suele estar unos cincuenta o setenta centímetros más abajo que el de la cocina. La razón de ser de este desnivel es que en el suelo de la corte se va acumulando el excremento de las vacas con el que se entremezclan capas vegetales de tojo o helechos. Esta mezcla - esterco- es almacenada y será utilizada en la época oportuna, como el principal abonado de los campos. Es por tanto importante el desnivel, para que este amasijo pueda ir creciendo sin desbordar. Entre corte y cocina había un muro en el que se practicaba una especie de ancha ventana, junto a la cual estaban los pesebres de las vacas, en los que se servía la hierba desde la cocina. Por este motivo, al entrar Gabriel desde fuera, por la puerta que da a la cocina, vio a través de la ventana las cabezas de los bueyes de labor, situados más abajo en la corte y cuyas cabezas, junto a la ventana de los pesebres, asomaban casi a flor del suelo de la cocina. Desde allí podían 
contemplar el desarrollo de la vida familiar en el principal ámbito de convivencia que era la cocina. Al mismo tiempo, la familia podía siempre observar, cuidar y alimentar cómodamente, con haces de hierba, al ganado vacuno, principal riqueza familiar.

Todo esto compone el sector dominante de "animalidad", que descubren los visitantes en la planta baja de la casa. Hay sin embargo, en su descripción, una parte que pertenece "a la humanidad en aquel recinto". La parte humana era el lar o baja meseta de piedra sobre la que se encendía el fuego, los bancos de madera - escanos- , la artesa y el horno del pan, taburetes, cuna de mimbre y leito. Este leito, llamado en muchas zonas "alcoba", tenía de ordinario la apariencia de un armario con una puerta o ventana a media altura, que una vez abierta servía de entrada para acostarse en la cama que se encontraba en su interior. Cerrando después las hojas de esta puerta, quedaban los durmientes defendidos en un ambiente cálido. En otras ocasiones, puede tener este recinto de madera alguna mayor amplitud, entrándose por una puerta de tamaño normal y quedando, entre la cama y las tablas de la pared, un pequeño espacio donde descalzarse o vestirse.

Además de estos elementos y mobiliarios de la "humanidad", en ambos casos se nos habla de una escalera de madera que "conducía al sobrado o cuarto altom. Este sobrado, dormitorio fundamental de la familia, constituía un piso, construido tan sólo sobre la corte y que ocupaba en el plano del edificio, junto con ella, una mitad semejante a la de la cocina: "Entraron en la cocina que ocupaba a la derecha tanto trecho como los establos y el sobrado". Suele ser de ordinario un espacio de celosa privacidad para la familia. De hecho, en la primera casa que se nos describe, los protagonistas no suben a él. Sí lo hacen en la segunda

\begin{abstract}
A la izquierda la subida al sobrado donde estaban las mejores habitaciones de la casa: una escalera endiablada y pina, por donde treparon todos, y tras ellos, a gatas, el chicuelo. Vieron el sobrado en dos minutos. Había el leito o cajón matrimonial, y la cama de la vieja, un brazado de paja fresca sobre una tarima; desde que se le había muerto su difuntiño, no podía dormir sino allí, porque tenía miedo en el antiguo leito. Los chiquillos dormirían [...] sabe Dios dónde; abajo, al calor del establo de los bueyes, o tal vez en el horno.
\end{abstract}

En este caso, como vemos, el leito o cajón matrimonial se encuentra en el sobrado y no en la cocina, junto con una cama y una tarima con paja fresca. Con toda claridad, se ha distinguido en estas descripciones el bajo, en el que se nota una pintoresca "mezcla de racionales e irracionales" de este otro ámbito, el sobrado, en el que están las mejores habitaciones de la casa. 
Detengámonos un momento a considerar las características de la selección descriptiva de elementos, de su ordenación en la secuencia narrativa y de los aportes interpretativos y explicativos de nuestra autora. Lo que trata de hacernos comprender es una manera de vivir o, mejor, diversas formas de vivir dentro del escenario geográfico de su obra. Su preocupación en este sentido es eminentemente antropológica. No puede ser más rotundo el contraste con cierto tipo de descripciones etnográficas donde los rasgos descontextualizados son ordenados en frías categorías que recuerdan las viejas salas de los antiguos museos, que albergan en vitrinas elementos disecados y desvitalizados que pertenecieron en tiempos al vivir humano. Por contra, los protagonistas aquí no son las cosas sino las personas, y éstas se introducen tan sólo en la manera que sirve a la autora para ayudarnos a comprender cómo viven o lo que todo aquello significa en el transcurrir de los humanos protagonistas. No en vano dirá, a través de la palabra de Gabriel, después de visitar una casa y de reconocer que ha disfrutado entrando allí:

me interesa..., pero no sabes cómo. ¿No te parece a ti que daría gusto ir entrando así en todas las casas de estas pobres gentes, una por una, y enterarse de lo que necesitan, de lo que quieren, de lo que piensan?

La prioridad está en comprender al ser humano en su marco espacial más íntimo. Para ello hace falta escudriñar el mundo de sentidos que nos permite comprender la tela de araña de la cultura.

Su plano de interpretación abarca, como hemos visto, diversos parámetros. Por una parte, marca insistentemente los distintos niveles sociales de riqueza y de poder. Es ya de por sí su contraste extraordinariamente sugestivo. Por otro, trata de comprender los mundos rurales como diferentes del que ella y muchos de sus lectores viven en la ciudad. Hay multitud de elementos sensoriales que contribuyen a situarnos en un medio cultural distinto. Pero además desentraña muchos de los íntimos sentidos de objetos y espacios, al destacar la manera de usar las gentes de ellos en su quehacer diario y contextualizarla en un marco de evocaciones vivenciales de las personas que describe. Las casas en decadencia, los sentimientos de sus habitantes y visitantes son comprendidos en la hilazón metonímica de elementos contrapuestos. Así, en el ambiente clerical de la rectoral empobrecida y, con extraordinario vigor, en la combinación de vieja riqueza y señorío, con deterioro y pobreza, del pazo de los Limiosos. Este juego de descripción etnográfica, intencionadamente interpretativa, inunda en multitud de capítulos el estudio del pazo de Ulloa. A través de ello, la cultura rural, polifónica y dinámica constituye un absorbente papel en el centro mismo de la trama argumental de la novela. 
Frente a las clases acomodadas, la forma de vivir de los labradores en sus casas es capaz de evocarnos, en unos pocos párrafos, problemas de notable envergadura teórica. Es la manera de vivir en cercanía animales y hombres, la forma de marcar espacios de naturaleza y cultura, las cotas de animalidad y suciedad de abajo en contraste con la limpieza del pequeño sobrado o el carácter minúsculamente humano del hogar y leito, los que nos sitúan en un juego de valores claramente distinto del ambiente urbano. Es, también, plenamente antropológica la manera de ordenar - en secuencia descriptiva en el texto- la forma en que sus humildes protagonistas dan orden a sus vidas, en el marco material y espacial de su vivir.

Esta continua distensión entre formas de valores procedentes de la ciudad y característicos del campo va a estar presente en casi todos los capítulos de la obra. Frente a una excesiva dicotomía en algunas formulaciones, la autora es capaz, con sutil finura, de ver cómo unas y otras se entremezclan ambiguamente en diferentes escenas de la vida. Tratemos de completar su itinerario interpretativo a través de su colorista descripción de algunas de las más destacadas costumbres.

Mi personal diálogo, como antropólogo, con las novelas de Dª Emilia, presenta una doble trayectoria. Por una parte, la comprensión desde mi propia etnografía y antropología de los valores claramente antropológicos de sus novelas. Sin duda, esta experiencia y preocupación disciplinar me permiten fijarme, valorar y admirar, desde una distinta perspectiva, la brillantez de sus descripciones e interpretaciones. La otra, es la manera cómo con sus datos confirma, contrasta o sirve de complemento y más amplio horizonte, a nuestra investigación etnográfica. Así ha sucedido a lo largo de las páginas descriptivas de viviendas que acabo de comentar. Y así ocurre, también, ante los enigmas que me han planteado ciertas costumbres, ceremoniales o rituales. Por ejemplo, la forma de casarse habitual en muchas zonas del campo gallego, hasta tiempos recientes. Todos mis informantes coinciden en afirmar que a las bodas se invitaba a muy poca gente. Se hacía incluso en horas que dificultaban la afluencia de personas extrañas y le daban un carácter cuasisecreto. Era eminentemente una ceremonia seria y, en no pocos casos y en ciertas zonas, se escenificaba la desgarradora despedida de los padres y -especialmente- de la madre de la novia que iba a marchar fuera de casa. He pensado durante mucho tiempo que esto era característica rural. $D^{\mathfrak{a}}$ Emilia, en cambio, me aporta una soberbia descripción del matrimonio aristocrático del señor de Ulloa y Nucha en Santiago, organizado por la familia urbana de la novia y en un ambiente típicamente santiagués. Leamos con detalle alguno de sus párrafos: 
Casáronse al anochecer, en una parroquia solitaria, vestía la novia de rico gro negro, mantilla de blonda y aderezo de brillantes. Al regresar hubo refresco para la familia y amigos íntimos solamente; un refresco a la antigua española... Dos candelabros con bujías, altos como mecheros de catafalco, solemnizaban el comedor; y los convidados, transidos aún del miedo que infunde el terrible sacramento del matrimonio visto de cerca, hablaban bajito, lo mismo que en un duelo, esmerándose en evitar hasta el repique de las cucharillas en la loza de los platos. Parecía aquello la comida postrera de los reos de muerte... todos estaban —es la frase de cajón- muy afectados...

Ciertamente la descripción de la Condesa manifiesta no poco de extrañeza, e incluso en algunos momentos, no está exenta de ironía. Parece, por tanto, que a ella también le resulta poco familiar este estilo. No sabemos si sería más característico de ciertos ambientes gallegos o santiagueses. Sí parece claro que lo considera como aceptado en el marco cultural de invitados que asisten a la boda y que incluso avanza una interpretación para ella relativamente razonable al hablar de el umiedo que infunde el terrible sacramento del matrimonio visto de cerca". Por mi parte, y en ambiente rural, suelo destacar como argumento explicativo el desgajamiento de la novia del ambiente familiar y ritualización de su despedida, así como el carácter de estrategia social problemática de las bodas en el juego de intereses económicos de la parroquia, que puede justificar el ambiente de sigilo, tanto del cortejo prematrimonial como de la propia celebración.

Veamos en contraste, la bellísima descripción que hace la autora de una típica fiesta parroquial. La fiesta de la parroquia de Naya se nos describe en primer lugar, atendiendo a sus aspectos decorativos preparatorios, en los que no falta el gaitero en el atrio mientras van llegando los curas de las parroquias cercanas: "Mientras en la iglesia, el hinojo esparcido por las losas y pisado por los que iban entrando despedía olor campestre y fresquísimo". Después de una breve procesión:

la misa empezó regocijada y rústica en armonía con los demás festejos. Más de una docena de curas la cantaban a voz en cuello. [...] Y momentos después, cuando el gaitero y los demás músicos vinieron a reclamar su parva o desayuno, el guiso de intestinos de castrón, hígado y bofes, llamado en el país mataburrillo [...] ¿Y qué valía todo ello en comparación del festín homérico preparado en la sala de la rectoral?. Media docena de tablas, tendidas sobre otros tantos cestos, ayudaban a ensanchar la mesa cotidiana. [...] La monumental sopa de pan, rehogada en grasa, con chorizo, garbanzos y huevos cocidos cortados en ruedas, circulaba ya en gigantescos tarterones [...] Grande fue su terror cuando empezó a desfilar interminable serie de platos, los ventiseis tradicionales en la comida del patrón de Naya, no la más abundante que se servía en el arciprestazgo, pues Loiro se le aventajaba mucho. [...] ¿Ventiseis platos? pronto se hace la lista: pollos asados, fritos, en pepitoria, estofados, con guisantes, con cebollas, con patatas y con huevos: aplí- 
quese el mismo sistema a la carne, al puerco, al pescado y al cabrito. Así, sin calentarse los cascos, presenta cualquiera ventiseis variados manjares.

En definitiva, como me ha sucedido ordinariamente en las invitaciones a participar en la comida de la fiesta parroquial, "la comilona amenazaba durar hasta el sol puesto". También sin llegar a tal alto número se me han servido en casas de labradores seis o siete platos de carne, seguidos de bollería. El prestigio fundamental de la fiesta suelen representarlo los variados tipos de carnes $y$, aunque se presente como complemento el alimento vegetal, éste es considerado impropio y se me suele insistir en que lo coma mínimamente:

¿hortalizas a mí!, diría el ama del cura de Cebre, riéndose con toda su alma y todas sus caderas también. Verduras el día del patrón son buenas para los cerdos.

El repertorio etnográfico de la Pardo Bazán es sencillamente sorprendente; tiene un conocimiento directo y minucioso de multitud de costumbres que entretejen toda su obra siempre encajadas en una trama vital contextualizadora. Por sus novelas desfilan los compostores y algebristas, especializados en sistemas curativos tradicionales de hombres y de animales, las sabias documentadas en multitud de medicinas, echadoras de cartas, deteniéndose incluso en algún llamativo análisis de su manera de predecir con las cartas. Refleja no pocas creencias populares: los cuentos de aparecidos, la compaña, las meigas o el trasgo, las costumbres de las serpientes de beber la leche de los niños son descritas con precisión. Las maneras de relacionarse con las estrellas que son como nosotros y el cuidado debido con los animales que

no tienen que ver con las personas: si no se cuidan y se asisten ni trabajan, ni dan leche, ni [...] Sin embargo a pesar de no ser como las personas bien se puede decir de alguien que era según frase del país "más gallego que las vacas".

Y para evitar los efectos de la envidia será buena cosa invocar el santo patrono de los animales al hablar laudatoriamente de ellos: "están bien lucidos, San Antón por delante. No tienen falta de médico".

Pero un especial cuidado y esmero tiene su atención a todo el calendario de faenas agrícolas. En todo momento es consciente de las tareas que en aquel momento se dan, con lo que la vida de sus protagonistas queda situada continuamente en el correcto marco estacional que le corresponde. Así, no se trata de individuos aislados ni descarnados en abstracción, sino de reales seres humanos en un marco de vida social según pautas de cultura. Como ejemplo especialmente significativo haré algunas referencias a la malla del cereal. Al preguntar D. Gabriel por su cuñado 
el señor de Ulloa a una moza, ésta extrañada por la pregunta en día tan destacado le contestó:

él está en la era.....jCon los que majan!. [...] No comprendía Gabriel el asombro de la chica y toda la importancia de la gran faena de la maja, esa faena en que se asocia el cielo y la estación estival al trabajo del hombre, esa faena que no puede realizarse sino en el corazón del año, en mitad de la canícula, en los brevísimos días, que en Galicia apenas llegarán a ocho, cuando el agricultor, pasándose el revés de la mano por la empañada frente y respirando fuerte, exclama: -iQué día de maja nos manda hoy Dios!

Ha captado nuestra autora la extraordinaria importancia de esta faena y la imperiosa necesidad de que se haga con la mayor brevedad posible aprovechando unos días sin lluvia que, al ablandar las espigas, harían imposible el trabajo. Es precisamente esta característica la que la convierte necesariamente en tarea cooperativa que concentra una numerosa mano de obra en el "mallado" del cereal de una sola casa. En las casas ricas o aristocráticas la afluencia de "clientes" que acudían a colaborar con el patrono solía ser muy destacada y acabar en una importante fiesta. La descripción atiende a detalles muy significativos que nos manifiestan la compleja utilidad que en Galicia, como en otras culturas ganaderas, puede tener el excremento de la vaca:

\begin{abstract}
No siendo de piedra la era, habíanla barnizado con una costra espesa de boñiga de vaca, al fin de que el fruto no se confundiese entre la arena y el polvo [...] las camadas de pan, óptimas, gruesas, mullidas se tendían sobre el espacio cuadrilongo, en correcta formación; y los membrudos gañanes, remangados, en dos hileras situadas frente a frente, aporreaban con sus pértigas, a compás, la extendida mies, haciendo saltar las perlas de oro del trigo, impacientes ya por salirse, con el menor pretexto, del estuche bruñido que las contiene. El sol implacable metálico se bebía el sudor de los trabajadores [...] todos los años, al abrirse la maja, acostumbraba el señor de Ulloa a sacudir la primera camada, demostrando así a sus gañanes, que si no ganaba el mismo jornal que ellos, no era por falta de aptitud.
\end{abstract}

A lo largo de toda la obra es tema dominante, analizado con todo lujo de perspectivas en diferentes situaciones y contextos, el asunto del poder. La marcada jerarquía social brilla con contundencia en todo momento. La obra presenta con riqueza las enrevesadas estrategias con las que los protagonistas compiten por conseguir el poder y controlarlo. Las estrategias se crean también a partir de un concreto mundo social y cultural. Toda la forma de actuar aparece impresa en un conjunto de normas y valores que expresan sensiblemente, de manera estrechamente formalizada, los estatus reconocidos e incluso las situaciones estratégicas del poder. El poder es estudiado dentro del pequeño microcosmos de la fa- 
milia y de las relaciones de señores y criados en la casa. Las artes políticas empleadas dentro de las clases más modestas se elevan en el horizonte de la historia política nacional con el reflejo que los grandes acontecimientos tienen en la pequeña geografía rural. Es allí donde cobran vida los caciques principales y secundarios, y sus enlaces con políticos a más alto nivel.

Es sin duda un entramado político-social que la autora domina a la perfección. En Los Pazos de Ulloa el criado mayordomo ha conseguido hacerse con las riendas del poder y convertirse en muchos aspectos en señor de su señor. Es la vieja inversión del papel del esclavo, sobradamente diseñada en la política aristotélica y retomada con fulgores dialécticos en la filosofía contemporánea. Su manera de argumentarlo en la obra es plenamente convincente. El criado sigue manteniendo los aspectos simbólicos formales con los que parece reconocer la superioridad de su amo, pero tanto el uno como el otro, como cualquier persona que entra a vivir en el pazo, según le sucede al sacerdote D. Julián, toma pronto plena conciencia de ello. La clave de su poder radica en un papel de intermediario con una numerosa concurrencia de clientes de clase baja, a través de la cual llega a detentar funciones de las que no puede prescindir su señor. Todo ese poder que se mueve clandestinamente por los destartalados salones del caserón, a lo largo de sus campos y en las relaciones aldeanas, queda presentado en contundente juego simbólico en multitud de escenas. La cocina, con todo el número de mujeres a las que la hija del mayordomo hace pequeños favores a costa del erario del marqués de Ulloa, es una contundente plasmación visual y escénica de la estrategia de poder. Este aplastante marco, apoyado en el clientelismo, se entrelaza con las otras redes caciquiles de la zona. Se convence al señor de Ulloa para que se presente a diputado. De nuevo aquí el mayordomo -Primitivo - adquiere paulatinamente un poder central. Un papel central que, de acuerdo con sus propios intereses, le lleva indefectiblemente a pasarse en el último momento al bando enemigo y producir la derrota política de su amo. Los curas y caciques derrotados, después de conocida la pérdida definitiva de la elección, se encuentran reunidos en casa del líder Barbacana analizando el sorpresivo proceso:

De repente un espantoso estruendo formado por los más discordantes y fieros ruidos que pueden desgarrar el tímpano humano asordó la estancia. Sartenes rascadas con tenedores y cucharas de hierro; tiestos de cocina tocados como címbalos; cacerolas, dentro de las cuales se agitaba en vertiginoso remolino un molinillo de batir chocolate; peroles de cobre, en que tañían broncas campanadas; fuertes manos de almirez; latas atadas a un cordel y arrastradas por el suelo; trébedes repicadas con varillas de hierro, $\mathrm{y}$, por cima de todo, la lúgubre y ronca 
voz del cuerno, y la horrenda vociferación de muchas gargantas humanas, con esa cavernosidad que comunica a la laringe el exceso de vino en el estómago [...] al través de las vidrieras de Barbacana, penetraba junto con el sonido de los hórridos instrumentos y descompasada gritería, vaho vinoso, el olor tabernario de aquella patulea, ebria de algo más que de triunfo [...] la cencerrada proseguía.

De nuevo la contundente escenificación simbólica del triunfo de las estrategias del poder. Sin embargo, los curas y caciques derrotados salen de improviso y lanzan un ataque:

clérigos y seglares se lanzaron contra la canalla, sin avisar ni dar voces, [...] blandiendo látigos y esgrimiendo barrotes [...] en todas direcciones huían los despavoridos borrachos chillando como si se los cargase un regimiento de caballería al galope $[. .$.

El mismo día Barbacana dará orden a su matón, el tuerto, de asesinar al traidor Primitivo.

Hemos ido recorriendo capítulos de análisis antropológico distendidos a lo largo de la narración. Todo ello queda subsumido y sintetizado en un esquema teórico existencial: el diálogo abrupto entre naturaleza y cultura. Es un mundo denso de pasiones el que lleva a los hombres a actuar dentro de esta tupida red de interacciones. Es la madre naturaleza expresada en el marco de la rusticidad aldeana y montañesa la que aporta el componente energético de la dinámica de la obra: el sórdido mayordomo es llamado precisamente Primitivo. Toda una urdimbre de amores, ambiciones, resentimientos y venganzas, idealismos místicos, sueños incumplidos, evocaciones y recuerdos melancólicos, parece fundir la naturaleza en sus moldes culturales, representados no pocas veces en el juego de la rusticidad aldeana y de la sofisticación urbana. En última instancia, nos aparecerá la paradoja dramática del incesto ignorado entre los dos adolescentes, la hija legítima de D. Pedro el señor de Ulloa y el hijo bastardo y encubierto que el mismo ha tenido con Sabel, la hija de Primitivo el mayordomo traidor.

Es toda una escenificación clásica a lo largo de la historia de las culturas, recogida en intensa teoría por Lévi-Strauss, la que nos brinda la fuerza teórica de claro sello antropológico en el conjunto de la obra. Es el incesto entendido como clara manifestación simbólica de animalidad o de naturaleza en la mayoría de los ambientes culturales, incluidos los que yo he estudiado en Galicia. Muchas veces los aldeanos gallegos emparentan en narraciones y en cánticos la acusación de incestuosos con los habitantes de las parroquias consideradas como más rurales y montañosas. Es el espíritu montaraz del señor de Ulloa y de sus hijos, es el ambiente rústico montañés, el descuido de una vida entregada a los amores y a la 
caza como opuesta a los ideales del místico capellán, la que se va a constituir en la cuna donde crece la relación incestuosa. Es la normativa y la vida cultural la que choca con ella. Pero ha sido la distensión entre estas dos pulsiones lo que ha dado origen a la vida humana de los protagonistas a lo largo de sus dos novelas. Una vida que ha sido capaz de encarnar magistralmente dentro de un concreta y veraz realidad cultural. Una cultura plural, tensional y cambiante. Una vida cultural dentro de la cual cabe interpretar espacios, objetos, normas y acciones como portadores de un mundo invisible de significados.

\section{BIBLIOGRAFÍA CITADA}

De la Fuente Lombo, Manuel (ed.). 1994. Etnoliteratura. Un nuevo método de análisis en Antropología. Córdoba: Servicio de Publicaciones de la Universidad de Córdoba.

- y M. á ÁNGEles Hermosilla ÁlvAREZ (eds.). 1997. Etnoliteratura: una antropología de ¿lo imaginario?. Córdoba: Servicio de Publicaciones de la Universidad de Córdoba.

PARDO BAZÁN, EmILA. 1995 [1886]. Los Pazos de Ulloa. Madrid: Alianza Editorial (18 reimpresión).

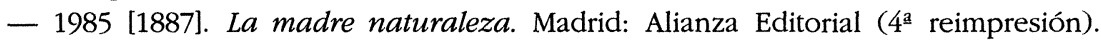

